Discussion: Based on agreements on cross-border emergency assistance between Nordic countries in mass-casualty and other major incidents, the countries have developed national capacities to deploy response teams to neighbor countries for on-scene assistance and medical evacuation. Planning of necessary talk groups is in progress, and practical testing will be performed during the Barents rescue exercise hosted by Sweden in 2019.

Prehosp Disaster Med 2019;34(Suppl. 1):s141-s142

doi:10.1017/S1049023X19003133

The Integration of a Unique $\mathrm{QR}^{\circledR}$ Code and Video to Improve the Correct Application of a Hemorrhage-control Tourniquet by a Naïve Population - A Feasibility Study

Dr. Paul Rega ${ }^{1}, M r$. Shaun Vallejo ${ }^{2}, M r$. John Accumanno ${ }^{3}$,

Dr. Brian Fink ${ }^{1}$

1. University of Toledo, Toledo, United States

2. Sparta Systems, Hamilton, United States

3. Cardinal Spellman High School, Bronx, United States

Introduction: The use of tourniquets by the civilian population has been deemed a critical aspect of the initial response during an active shooter situation. Tourniquet deployment in public-access must be accompanied by education. Studies indicate that the act itself is not an intuitive process and enclosed instructions may be inadequate. However, civilians for diverse reasons may not avail themselves of accepted training programs.

Aim: To develop an alternative means of "Just-In-Time" education to enable a naïve responder to apply a commercial tourniquet efficaciously.

Methods: A video ( 40 seconds long) was created highlighting the actual application of a C-A-T ${ }^{\circledR}$ (Combat Application Tourniquet) on a human model. It was uploaded to YouTube on a public channel. $\mathrm{A} \mathrm{QR}^{\circledR}$ code was generated using https://www.qr-code-generator.com, embedding the link for the YouTube ${ }^{\circledR}$ video. An appropriately-sized $\mathrm{QR}^{\circledR}$ code was printed and applied with packaging tape $\left(\mathrm{Scotch}^{\circledR}\right)$ to the exterior wrapping of a $\mathrm{C}-\mathrm{A}-\mathrm{T}^{\circledR}$ device. The $\mathrm{C}-\mathrm{A}-\mathrm{T}^{\circledR}{ }_{\text {with }}$ code was then accessed with the iPhone ${ }^{\circledR}$.

Results: With the iPhone ${ }^{\circledR}$ camera app activated and focused on the C-A-T's $\mathrm{QR}^{\circledR}$ code, a request popped-up to open "YouTube.com" in Safari. When pressed, the full-screen video appeared immediately with audio of excellent quality.

Discussion: The use of a $Q R^{\circledR}$ code and its video link is a feasible option to provide "Just-In-Time" training to a naïve civilian population who are responding to an active shooter situation. This offers the naïve responder two options of immediate education: the enclosed instructions and the $\mathrm{QR}^{\circledR}$ code. Redundancy in communications is essential in any emergency response. An important limitation of this innovation is the inability to obtain Internet ${ }^{\circledR}$ access and therefore, the availability of the enclosed instructions is still critical. Research to prove that this innovation will allow the application of a tourniquet to proceed expeditiously with few errors is currently underway.

Prehosp Disaster Med 2019;34(Suppl. 1):s142

doi:10.1017/S1049023X19003145
Introduction of Japanese Association of Disaster Medicine (JADM) Disaster Medical Coordination Support Team Mr. Yoshiki Toyokuni ${ }^{1}$, Dr. Yuichi Koido ${ }^{1}$, Dr. Hisayoshi Kondo ${ }^{1}$, Dr. Tomohiko Mase ${ }^{2}, M r$. Shota Kasai ${ }^{1}$

1. Japanese Association for Disaster Medicine, Chuo-ku, Japan

2. Iwate Medical University, Yahaba, Japan

Introduction: The Japanese Association for Disaster Medicine (JADM) Disaster Medical Coordination Support Team (DMCST) was formed in 2016 when Japan experienced Kumamoto earthquake to support other disaster medical assistance teams in terms of headquarter operation logistics.

Aim: Introducing medical association-based disaster medical support team.

Methods: JADM DMCST was formed by an association member who had experience in disaster medical headquarter operation and logistic support. Disaster medical headquarter tends to have a gap between acute phase and sub-acute phase due to an alternation of disaster medical assistance team. To keep disaster medical management at medical management headquarter, experienced manpower requires. JADM DMCST provided assistance to fill those gaps.

Results: For 2016 Kumamoto Earthquake, 107 members responded as a JADM DMCST, 78 members responded for 2018 West Japan Torrential Rain Disaster. Most of the members responded to the medical headquarter of affected prefecture's, city's, and medical region's headquarters. Members provided logistic support in headquarter operation, gathered medical needs information, helped medical team dispatch coordination, gathered evacuation shelter information, provided heat stroke support for evacuees, assisted deep vein thrombosis management, provided AED delivery operation, and helped statistical information analysis based on WHO standards.

Discussion: JAMD DMCST could provide medical management support at each headquarters without time span restrictions which the most of disaster medical assistance team has. Since all members were experienced in disaster medical management, they could connect and keep providing medical assistance to the affected people. At the time of disaster, disaster medical management headquarter is always short handed due to a large amount of incoming information. All this information was managed by the support team. Although JADM DMCST contributed to support headquarter management, each member had to pay for his/her transportation, hotel, food and any devices required for headquarter operations. Therefore, improving member's responding condition is next problem to solve.

Prehosp Disaster Med 2019;34(Suppl. 1):s142

doi:10.1017/S1049023X19003157

\section{An Introduction to Coastal Wilderness Medicine: BEACCHEs}

Dr. Upuli Pahalawatta ${ }^{2}$, Dr. Amanda Dawson ${ }^{1}$

1. Central Coast Medical School, University Of Newcastle, Gosford, Australia

2. Central Coast Local Health District, Gosford, Australia

Introduction: Beginning Education at Central Coast Hospitals (BEACCHEs) was developed as an experiential 